\title{
Production of Antifungal and Antibacterial Substances by Fungi; Preliminary Examination of 166 Strains of Fungi Imperfecti
}

\author{
By P. W. BRIAN AND H. G. HEMMING \\ Imperial Chemical Industries Ltd., Butterwick Research Laboratories, Welwyn, Herts
}

SUMMARY: One hundred and sixty-six strains of Fungi Imperfecti have been examined primarily for the production of antifungal substances, though antibacterial substances have also been sought in most cases.

Antifungal substances were produced by several species of Aspergillus and Penicillium, Fusarium caeruleum, Metarrhizium glutinosum, Stachybotrys atra, Trichoderma viride, Gliocladium catenulatum and Trichothecium roseum. Antibacterial substances were produced by species of Aspergillus, Fusarium, Penicillium, Stachybotrys and Trichoderma.

The chemical nature of the substances responsible for this activity is known or can be suggested in some cases, but others are worthy of further investigation.

Several surveys of the production of antibacterial substances by fungi have been published recently (Wilkins \& Harris, 1942, 1943, 1944 $a, b, c$; Wilkins, 1945, 1946; Robbins, Hervey, Davidson, Ma \& Robbins, 1945), from which it appears that many of the Ascomycetes, Basidiomycetes and Fungi Imperfecti show marked antibacterial activity but few, if any, of the Phycomycetes. No comparable surveys of the production of antifungal substances have been published, though many substances originally studied for their antibacterial activity have since been found to be also toxic to fungi. The present account deals with a number of Fungi Imperfecti examined primarily for antifungal activity; a preliminary examination for antibacterial activity has also been made in most cases. Species of Penicillium, Aspergillus and Trichoderma account for a high proportion of the strains examined, but representatives of seventeen other form-genera have been included. Further studies of certain of the strains found to produce antifungal substances have resulted in the isolation in pure form of the antibiotics viridin, glutinosin, gladiolic acid and 'curlingfactor'; the relevant references to this work are given in a later section of this paper.

\section{EXPERIMENTAL MATERIALS AND METHODS}

The fungi examined were obtained from various sources. Many were isolated in this laboratory from soils or other materials, and many were obtained from the National Collection of Type Cultures. The writers are also indebted to Dr G. R. Bisby for cultures of Trichoderma, Stachybotrys and Memnoniella and to Mr George Smith for cultures of Trichoderma and Gliocladium. All identifications have been checked as far as possible and a number of the more interesting Penicillia ( $\boldsymbol{P}$. terlikowskii and members of the $\boldsymbol{P}$. nigricans- 
janczeroskii series) have been submitted for identification to Dr K. B. Raper of the United States Department of Agriculture.

The antifungal and antibacterial properties of these fungi have been examined in most cases by two methods. The first and most simple method was by observation of antagonisms in agar-plate cultures. The second method involved growing the fungi on liquid media with periodical assays of the culture filtrates for antifungal and antibacterial activity. These methods are described in greater detail below.

\section{Antagonism in agar culture}

The agar medium used had the following composition: glucose $10 \mathrm{~g}$.; peptone (Evans Medical Supplies, London) 10 g.; Lab-Lemco meat extract 3 g.; sodium chloride $5 \mathrm{~g}$.; agar $15 \mathrm{~g}$.; distilled water $1000 \mathrm{ml}$. Plates of this medium were inoculated with a transverse streak of spores of the fungus to be examined, or by a mycelial transplant if spores were not sufficiently abundantly produced. The inoculated plates were incubated for 4 days at $25^{\circ}$. Using a platinum loop, $\mathbf{2 4} \mathrm{hr}$. broth cultures of two bacteria (Staphylococcus aureus and Salmonella typhi) and a suspension in sterile broth of cell material of the animal-pathogenic fungus Endomycopsis albicans (Vuill.) Dekker, were then streaked at right angles to the advancing edge of the fungus colony. The plates were incubated for a further $24-28 \mathrm{hr}$. at $37^{\circ}$ after which they were examined and the degree of antagonism, as represented by the presence or absence, adjacent to the fungus colony, of a clear zone where no growth of the test organism had taken place, recorded as follows:

- = no indication of antagonism,

$+=$ zone of inhibition not more than $0.5 \mathrm{~cm}$.,

$++=$ zone of inhibition greater than $0.5 \mathrm{~cm}$.,

$(+)=$ an apparent diminution in vigour of growth of the test organism without production of a clear zone, observed in some tests.

\section{The liquid culture method}

The mould to be examined was grown on $30 \mathrm{ml}$. lots of medium dispensed in $100 \mathrm{ml}$. Pyrex flasks. In some of the earlier experiments $15 \mathrm{ml}$. of medium in $9 \mathrm{~cm}$. Petri dishes was used (cf. Weindling, 1934), but this method was discarded because of the prevalence of contaminations and difficulty of handling. In general 20-25 flasks of each medium used were inoculated, incubated at $25^{\circ}$, and five were withdrawn at random and bulked for assay. Samples were taken in this manner usually after $6,8,10$ and 12 days' incubation; with some more rapidly growing forms (e.g. Trichoderma) sampling was begun earlier, and was carried on longer (up to 21 days) with the more slowly growing organisms. The liquid medium was filtered off and assayed for fungistatic activity by the Botrytis allii spore-germination technique (Brian \& Hemming, 1945) and for antibacterial activity by the usual serial dilution technique, using Staphylococcus aureus as test organism, growth being estimated turbidimetrically. 
The media used in this work have been varied from time to time as experience was gained and bearing in mind, in some cases, known preferences of some of the organisms. The media used were Weindling, Weindling N, Czapek-Dox, Raulin-Thom, Cornsteep and Barham \& Smits. Of these, the composition of Weindling, Czapek-Dox, Raulin-Thom and Cornsteep have been previously given (Brian, Curtis \& Hemming, 1946). Weindling $\mathbf{N}$ is a variant of the standard Weindling medium with the same amount of nitrogen supplied as sodium nitrate instead of as ammonium tartrate. The Barham \& Smits medium is one with high sugar content recommended (Barham \& Smits, 1936) for production of kojic acid by Aspergillus flavus.

\section{RESULTS}

The results are summarized in Table 1. To economize in space the results of all assays have not been given but only the highest assay observed at any of the samplings. The activities of culture filtrates are indicated as follows:

2 signifies inhibition of spore germination or bacterial growth at a dilution of 1 in 4 ( 1 in $\left.2^{2}\right)$ but not at 1 in 8 ,

3 significs inhibition of spore germination or bacterial growth at a dilution of 1 in 8 ( 1 in $2^{3}$ ) but not at 1 in 16 ,

and so on accordingly. In the case of the $B$. allii spore-germination test the least dilution examined was 1 in 2; activity at this level but not at 1 in 4 was recorded as activity 1 , no activity at 1 in 2 was recorded as 0 . In the case of the antibacterial tests the results of the first dilution were ignored on all media and of the first two dilutions with Raulin-Thom and Weindling, as the culture medium alone was found to inhibit growth on occasion; activity 0 represents, therefore, no activity at a dilution of 1 in 8 with culture filtrates from RaulinThom and Weindling, no activity at 1 in 4 for all other media.

\section{Detailed consideration of results}

The fungi examined can most conveniently be discussed in groups.

Aspergillus. Only three strains of Aspergillus of the 22 examined showed any marked activity when grown on liquid media, though several more were active in agar culture. A strain of $A$. clavatus (no. 88) showed both antifungal and antibacterial activity. Strains of this species have been shown (Katzman, Hayes, Cain, van Wyk, Reithel, Thayer, Doisy, Gaby, Carroll, Muir, Jones \& Wade, 1944; Waksman, Horning \& Spencer, 1943) to produce the antibiotic substance known as clavacin or patulin (anhydro-3-hydroxymethylenetetrahydro-1:4-pyrone-2-carboxylic acid) and it is the production of this substance which probably accounts for the effects observed.

Two strains of $A$. terreus (nos. 278 and 279) possess marked antifungal and antibacterial activity. This species is biochemically very versatile and substances isolated from its culture filtrates include clavacin (Kent \& Heatley, 1945), citrinin (Timonin, 1942; Thom \& Raper, 1945) and itaconic acid (Calam, 
Oxford \& Raistrick, 1939), all of which are known to possess antifungal and antibacterial properties.

Fusarium. F. caeruleum apparently produces an antifungal substance, though subsequent experiments have given conflicting results. Three unidentified Fusarium spp. (nos. 37, 42 and 47) produce an antibacterial substance. Little work has been reported on the isolation of antibiotics produced by Fusarium spp., though Arnstein, Cook \& Lacey (1946) have recently reported the isolation of an antibacterial pigment-javanicin $\left(\mathrm{C}_{15} \mathrm{H}_{14} \mathrm{O}_{6}\right)$-from culture filtrates from liquid culture of $F$. javanicum.

Metarhizium. M. glutinosum showed marked antifungal activity but no antibacterial activity. The isolation of an antifungal substance, glutinosin $\left(\mathrm{C}_{42} \mathrm{H}_{60} \mathrm{O}_{16}\right)$, from culture filtrates, has already been reported (Brian \& McGowan, 1946).

Penicillium. The strains falling into the $P$. chrysogenum series (nos. 25, 26, 76,238 and probably also 182 and 188) show marked antibacterial activity (to Staphylococcus aureus but not to Salmonella typhi in the agar culture test) but no antifungal activity. This is almost certainly due to penicillin production. The slight antibacterial activity shown by Penicillium citrinum (no. 54) is probably due to production of citrinin and the moderate antifungal and antibacterial activity of strains of $\boldsymbol{P}$. cyclopium and $\boldsymbol{P}$. puberulum to production of penicillic acid $\left(\gamma\right.$-keto- $\beta$-methoxy- $\delta$-methylene- $\Delta^{\alpha}$-hexenoic acid) (Alsberg $\&$ Black, 1913; Birkinshaw, Oxford \& Raistrick, 1936).

Several strains of $\boldsymbol{P}$. expansum showed antibacterial activity; Anslow, Raistrick \& Smith (1943) have shown that strains of this mould produce clavacin (patulin). Both strains of $\boldsymbol{P}$. gladioli examined were actively antifungal and antibacterial; Brian, Curtis, Grove, Hemming \& McGrowan (1946) have shown this to be due to production of gladiolic acid $\left(\mathrm{C}_{11} \mathrm{H}_{10} \mathrm{O}_{5}\right)$, which they have isolated in pure form. Six strains of P. janczerwskii were examined, all of which save one had been isolated from Wareham Heath soil. Though the antifungal activity as expressed by suppression of spore germination was only moderate, they all produced extraordinary distortions of Botrytis allii hyphae. A pure substance ('curling-factor') responsible for this interesting physiological effect has been isolated (Brian et al. 1946; McGowan, 1946). Two related strains of the $\boldsymbol{P}$. nigricans-janczewskii series produce antibacterial and antifungal culture filtrates, without the distorting effect; these are at present the subject of investigation.

The marked antifungal and antibacterial activity of $\boldsymbol{P}$. terlikowskii has been shown (Brian, Hemming \& McGowan, 1945; Brian, 1946) to be due to production of gliotoxin $\left(\mathrm{C}_{13} \mathrm{H}_{14} \mathrm{~N}_{2} \mathrm{~S}_{2} \mathrm{O}_{4}\right)$.

$P$. lilacinum is interesting in that it has shown marked antagonistic effects in agar culture but when grown in liquid culture the culture filtrates have shown little if any activity. In addition to those already mentioned a number of other Penicillium spp. have shown slight antifungal or antibacterial activity, but no further comment is at present possible.

Stachybotrys and Memnoniella. Of nine strains of Stachybotrys atra examined six show antifungal or antibacterial activity. The remaining six strains, and 

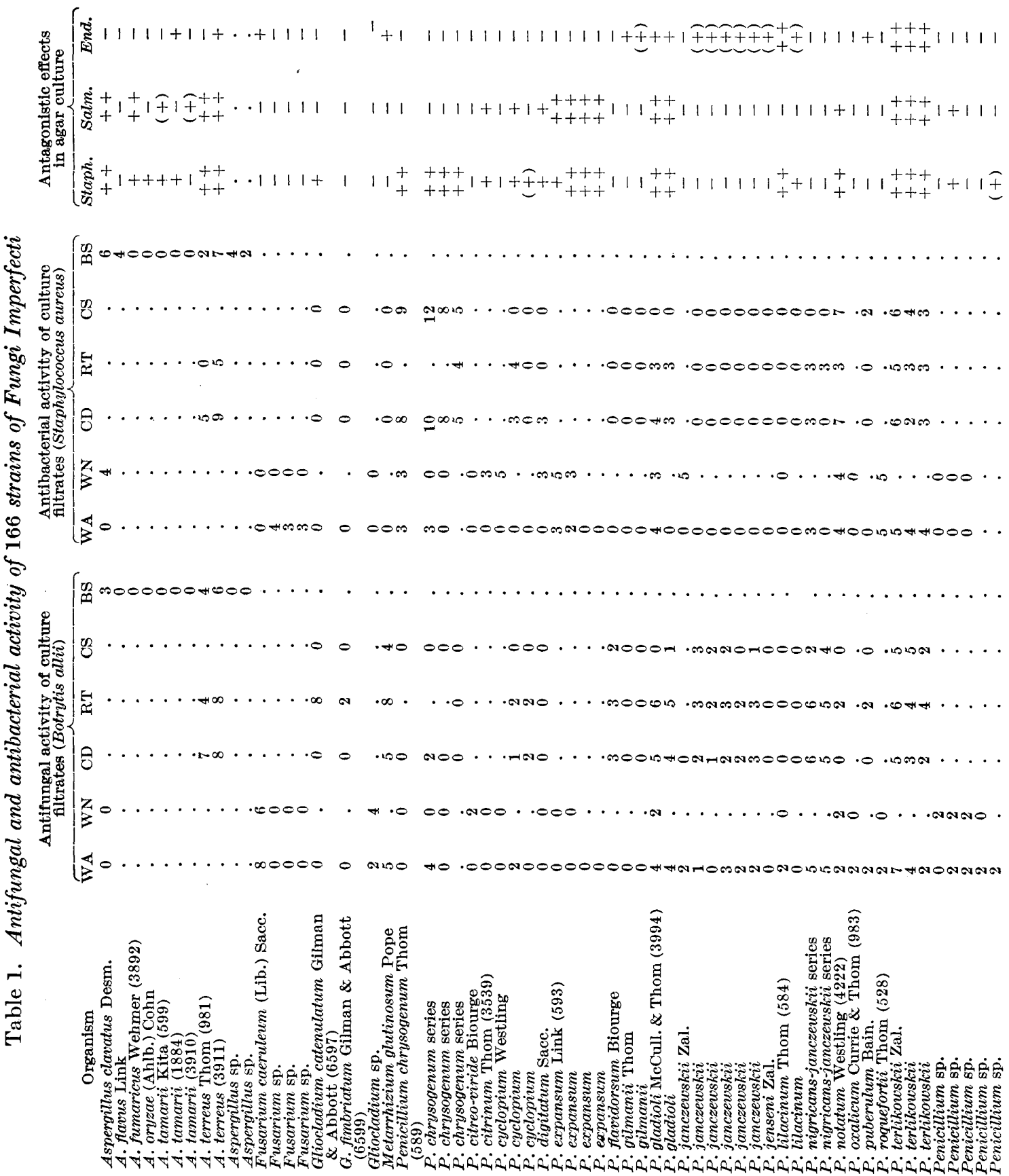

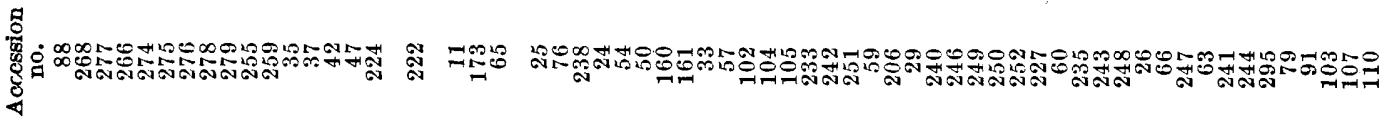




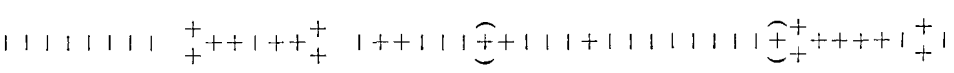

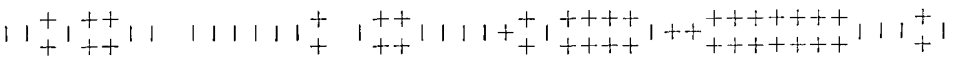

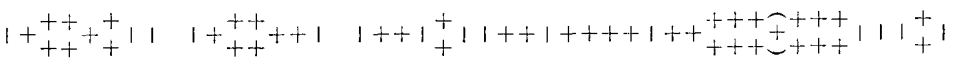
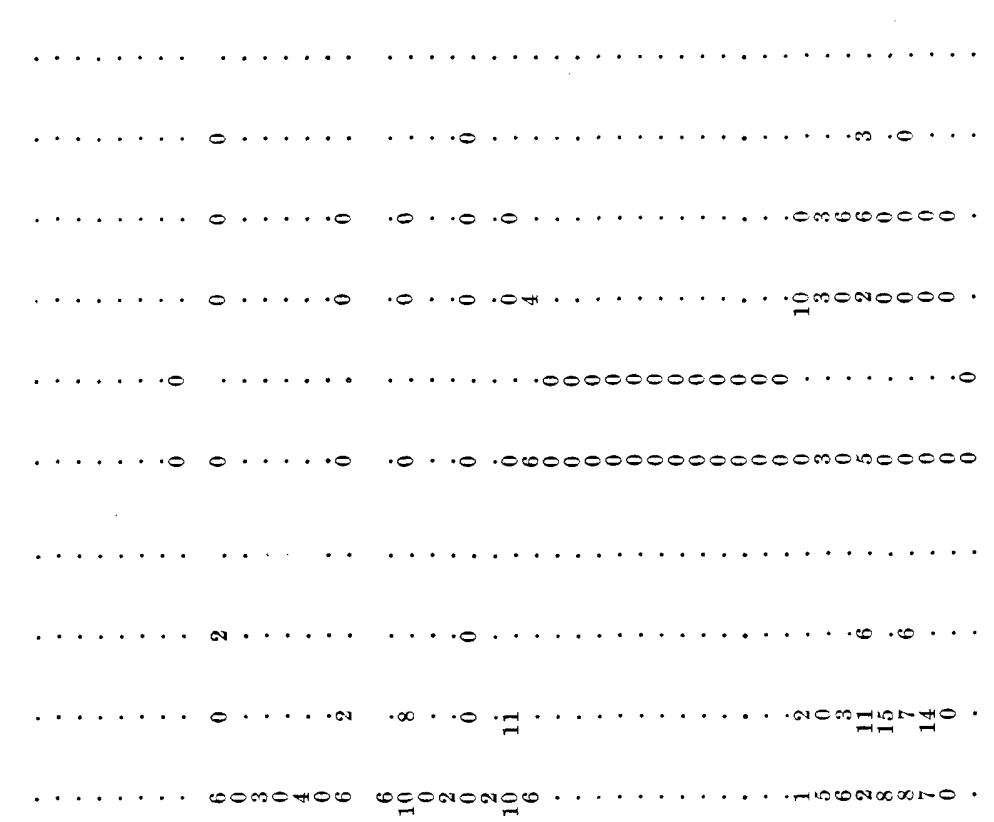

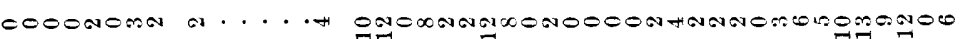

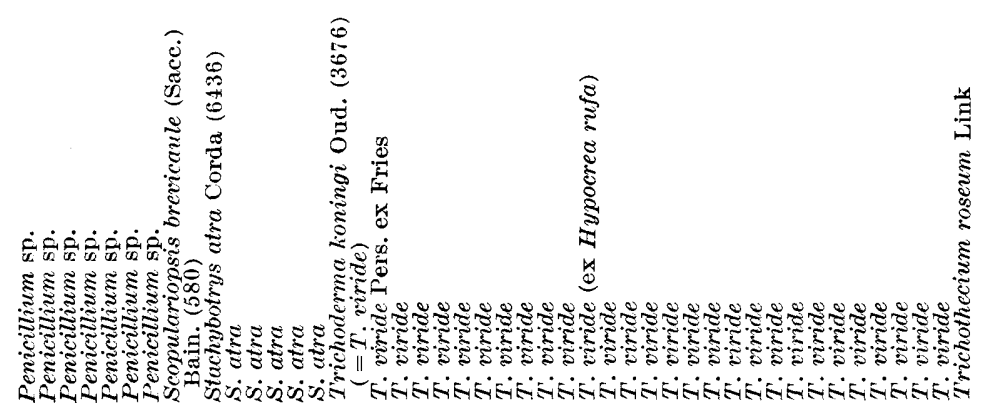

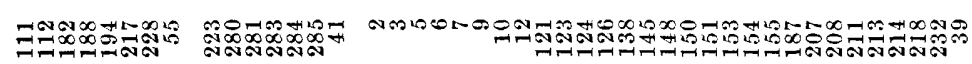

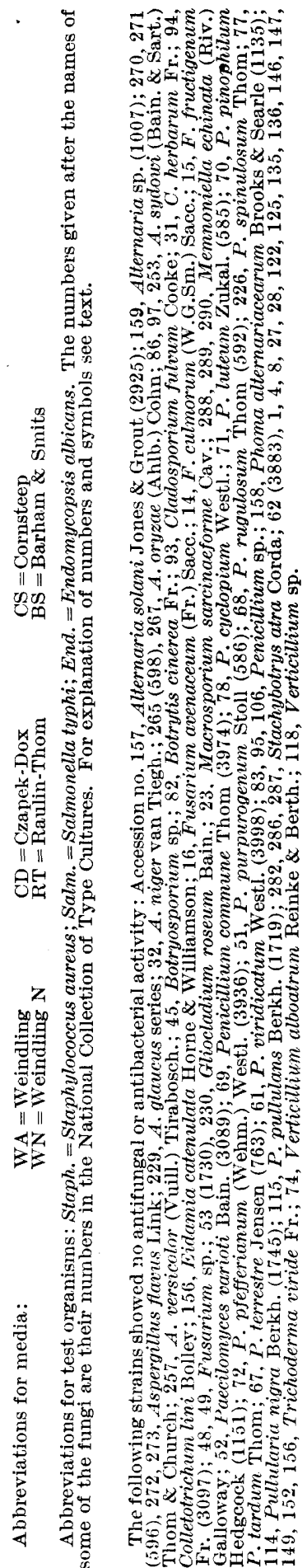


three strains of Memnoniella echinata, included because of the possible identity of this form with Stachybotrys atra (Bisby, 1943, 1945; Zuck, 1946), showed neither type of activity. $S$. atra is at present being studied in greater detail.

Trichoderma and Gliocladium. Three well-defined groups can be seen in Trichoderma:

Group 1 : showing marked antifungal activity but no antibacterial activity. This includes strains 2, 3, 10, 213, 214 and 218.

Group 2: showing both antifungal and antibacterial activity. This includes strains 12, 207, 208, 211.

Group 3: showing no activity, either on agar or in liquid culture. This, the largest group, includes strains 1, 4, 8, 27, 28, 62, 122, 125, 135, 136, 146, 147, 149,152 and 156.

The strains in group 1 are all of the pigmented type; this type of activity is probably due to the production of viridin (Brian \& McGowan, 1945; Brian, Hemming, Curtis \& McGowan, 1946). Strains 3, 10, 213 and 214 are known to produce viridin. The strains in group 2 are all non-pigmented and probably all produce gliotoxin, which is both antibacterial and antifungal. Strains 12, 207 and 211 are known to produce this substance (Brian, 1944; Brian \& Hemming, 1945).

In addition to these well-defined groups there are many strains which show various types of activity in agar culture but none when grown on liquid media. This effect is also to be noticed with fungi from other genera. One strain in particular is worth noting, no. 7, which appears to produce a substance active against Staphylococcus but not against Salmonella or the test fungi, suggesting that viridin and gliotoxin may not be the only antibiotic substances produced by Trichoderma viride.

The probable identity of Weindling's 'Gliocladium fimbriatum', from which gliotoxin was first isolated, with Trichoderma viride, has been discussed elsewhere (Brian, 1944). It is of interest here to note that an authentic Gliocladium fimbriatum shows very slight antifungal activity, but that $G$. catenulatum is distinctly more active in this respect and is worth further investigation.

Other fungi. Fungi from other form-genera have all given negative results with the exception of Trichothecium roseum which produced antifungal culture filtrates. The antagonistic properties of this organism have been previously reported by Greaney \& Machacek (1935).

\section{General observations}

As previously mentioned this survey has been carried out primarily to obtain information on the production of antifungal substances by moulds. Approximately one-third of the strains examined show antifungal activity. This proportion is weighted by the fact that where a species showed promise considerable numbers of strains were examined (especially in Trichoderma). After making due allowance for this, however, it will be seen that quite a high proportion of Fungi Imperfecti produce substances toxic to another mould (Botrytis allii). 
Two limitations in the technique must also be borne in mind when considering the general implication of these results. First, only one test fungus has been used in the liquid culture experiments-Botrytis allii. It is possible that a completely different picture might have been obtained if other test fungi had been used. No definite judgement on this possibility can be made at present but the antifungal metabolic products which have been isolated in these laboratories (viridin, glutinosin, gladiolic acid and 'curling-factor') and others are generally active against most fungi other than the one specifically producing them. This technical limitation, then, may not be of great importance.

A more important limitation undoubtedly is that the spore-germination tests have all been carried out at $\mathrm{pH} 3.5$ and acid-sensitive antifungal materials might well be destroyed under those conditions. The numerous recorded discrepancies between the agar culture method (carried out at $\mathrm{pH} \mathrm{6.5-7)}$ and the liquid culture method may be due to this. In future surveys it is proposed to carry out assays at $\mathrm{pH} 3.5$ and at $\mathrm{pH} 6.5$ or 7.0 so that both acid-sensitive substances and those stable only in acid solutions (e.g. viridin) can be detected.

Most of this work was carried out at Hawthorndale Laboratories, Jealott's Hill Research Station. We are indebted to Miss Myrtle Bray and Miss M. W. Weller for assistance with the biological assays.

\section{REFERENCES}

Alsberg, C. L. \& Black, O. F. (1913). Contributions to the study of maize deterioration. Bull. U.S. Bur. Pl. Ind. no. 270, pp. 1-48.

Anslow, W. K., Raistrick, H. \& Sмrтh, G. (1943). Antifugal substances from moulds; patulin (anhydro-3-hydroxymethylene-tetrahydro-1:4-pyrone-2-carboxylic acid), a metabolic product of Penicillium patulum Bainier and Penicillium expansum (Link) Thom. J. Soc. chem. Ind. 62, 236.

Arnstein, H. R. V., Cook, A. H. \& Lacey, M. S. (1946). An antibacterial pigment from Fusarium javanicum. Nature, Lond., 157, 333.

Bariam, H. N. \& Smirs, B. L. (1936). Production of kojic acid from xylose by Aspergillus flavus. Industr. Engng Chem. 28, 567.

Birkinshaw, J. H., Oxford, A. E. \& Raistrick, H. (1936). Studies in the biochemistry of micro-organisms. XLVIII. Penicillic acid, a metabolic product of Penicillium puberulum Bainier and P. cyclopium Westling. Biochem. J. 30, 394-411.

Bisby, G. R. (1943). Stachybotrys. Trans. Brit. mycol. Soc. 26, 133.

Bissy, G. R. (1945). Stachybotrys and Memnoniella. Trans. Brit. mycol. Soc. 28, 11.

Brian, P. W. (1944). Production of gliotoxin by Trichoderma viride. Nature, Lond., $154,667$.

Brian, P. W. (1946). Production of gliotoxin by Penicillium terlikoreskii Zal. Trans. Brit. mycol. Soc. (in the Press).

Brian, P. W., Curtis, P. J., Grove, J. F., Hemming, H. G. \& McGowan, J. C. (1946). Gladiolic acid: an antifungal and antibacterial metabolic product of Penicillium gladioli McCull \& Thom. Nature, Lond., 157, 697. 
Brian, P. W., Curtis, P. J. \& Hemming, H. G. (1946). A substance causing abnormal development of fungal hyphae produced by Pencillium janczereskii Zal. I. Biological assay, production and isolation of 'curling-factor'. Trans. Brit. mycol. Soc. $29,173$.

Brian, P. W. \& Hemming, H. G. (1945). Gliotoxin, a fungistatic metabolic product of Trichoderma viride. Ann. appl. Biol. 32, 214.

Brian, P. W., Hemming, H. G., Curtis, P. J. \& McGowan, J. C. (1946). The production of viridin by pigment-forming strains of Trichoderma viride. Ann. appl. Biol. 33, 190.

Brian, P. W., Hemming, H. G. \& McGowan, J. C. (1945). Origin of a toxicity to mycorrhiza in Wareham Heath soil. Nature, Lond., 155, 637.

Brian, P. W. \& McGowan, J. C. (1945). Viridin: a highly fungistatic substance produced by Trichoderma viride. Nature, Lond., 156, 144.

Brian, P. W. \& McGowan, J. C. (1946). Biologically active metabolic products of the mould Metarrhizium glutinosum S. Pope. Nature, Lond., 157, 334.

Calam, C. T., Oxford, A. E. \& Raistrick, H. (1939). Studies in the biochemistry of micro-organisms. LXIII. Itaconic acid, a metabolic product of a strain of Aspergillus terreus Thom. Biochem. J. 33, 1488.

Greaney, F. J. \& MachaceK, J. E. (1935). Studies on the control of the root-rot diseases of cereals caused by Fusarium culmorum (W.G.Sm.) Sacc. and Helminthosporium sativum P.K. \& B. Sci. Agric. 15, 377.

Katzman, P. A., Hayes, E. E., Cain, C. K., van Wyk, J. J., Reithel, F. J., Thayer, S. A., Doisy, E. A., Gaby, W. L., Carroll, C. J., Muir, R. D., Jones, L. R. \& WADE, N. J. (1944). Clavacin, an antibiotic substance from Aspergillus clavatus. J. biol. Chem. 154, 475.

Kent, J. \& Heatley, N. G. (1945). Antibiotics from moulds. Nature, Lond., 156, 295.

McGowan, J. C. (1946). A substance causing abnormal development of fungal hyphae produced by Penicillium janczereskii Zal. II. Preliminary notes on the chemical and physical properties of 'curling-factor'. Trans. Brit. mycol. Soc. 29, 188.

Robbins, W. J., Hervey, A., Davidson, R. W., MA, R. \& Robbins, W. C. (1945). A survey of some wood-destroying and other fungi for antibacterial activity. Bull. Torrey bot. Cl. 72, 165.

Thом, C. \& Raper, K. B. (1945). A Manual of the Aspergilli. London: Baillière, Tindall and Cox.

Trmonin, M. I. (1942). Another mould with antibacterial ability. Science, 96, 494.

Waksman, S. A., Horning, E. S. \& Spencer, E. L. (1943). Two antagonistic fungi, Aspergillus fumigatus and $A$. clavatus, and their antibiotic substance. J. Bact. 45, 233.

Weindling, R. (1934). Studies on a lethal principle effective in the parasitic action of Trichoderma lignorum on Rhizoctonia solani and other soil fungi. Phytopathology, 24, 1153.

Wilkins, W. H. (1945). Investigation into the production of bacteriostatic substances by fungi. Cultural work on Basidiomycetes. Trans. Brit. mycol. Soc. 28, 110.

WiLkINs, W. H. (1946). Investigation into the production of bacteriostatic substances by fungi. Preliminary examination of more of the larger Basidiomycetes and some of the larger Ascomycetes. Ann. appl. Biol. 33, 188.

Wilkins, W. H. \& Harris, G. C. M. (1942). Investigation into the production of bacteriostatic substances by fungi. Preliminary examination of 100 fungal species. Brit. J. exp. Path. 23, 166.

Wilkins, W. H. \& Harris, G. C. M. (1943). Investigation into the production of bacteriostatic substances by fungi. Preliminary examination of a second 100 fungal species. Brit. J. exp. Path. 24, 141. 
Wilkins, W. H. \& Harris, G. C. M. (1944a). Investigation into the production of bacteriostatic substances by fungi. Preliminary examination of the third 100 fungi with special reference to strain variation among species of Aspergillus. Trans. Brit. mycol. Soc. 27, 113.

Wilkins, W. H. \& Harris, G. C. M. (1944b). Investigation into the production of bacteriostatic substances by fungi. Preliminary examination of a fourth 100 species, all Penicillia. Brit. J. exp. Path. 25, 135.

Wilkins, W. H. \& Harris, G. C. M. $(\mathbf{1 9 4 4} c)$. Investigation into the production of bacteriostatic substances by fungi. Examination of the larger Basidiomycetes. Ann. appl. Biol. 31, 261.

Zuck, R. K. (1946). Isolates intermediate between Stachybotrys and Memnoniella. Mycologia, 38, 69. 